(2) Open Access Full Text Article

\title{
Analysis of Clinical Trials of New Drugs for Liver Diseases in China
}

\section{Longfei Lin}

Hui Li

Institute Chinese materia medica china academy of Chinese medical sciences, Beijing, People's Republic of China
Correspondence: Hui Li Institute Chinese materia medica china academy of Chinese medical sciences, Dongcheng District Dongzhimen

Nanxiaojie Within 16, Beijing, People's Republic of China

Tel + 861064087670

Fax + 861064032658

Email lihuizys@126.com
Background: Liver diseases are a major public health concern worldwide, and the development of novel therapeutic drugs is an important research focus. But no overview has been conducted so far on the current research and development for liver-specific drugs in China, and the actual situation regarding the development and evaluation of new drugs in clinical trials.

Methods: The information of all clinical trials on liver diseases were obtained through the "Pharmaceutical Clinical Trial Registration and Information Disclosure Platform" before December 31, 2020.

Results: A total of 751 clinical trials on liver disease-related drugs were published on the above platform, including 574 chemical drugs, 128 biological products, and 49 traditional Chinese medicine (TCM)/natural drugs. The number of annual registrations has increased on an annual basis. The main indications for these clinical trials are viral hepatitis, liver malignancies, liver abscess, liver transplantation, congenital liver metabolic disease, and other hepatitis-related diseases. Hepatitis B, hepatitis C and liver cancer accounted for $72.4 \%$ of the total clinical trials, and the majority are related to generic drug research. There are 103 innovative drugs currently in clinical testing, mainly for hepatitis $\mathrm{B}$, hepatitis $\mathrm{C}$ and hepatocellular carcinoma.

Conclusion: The stronger macro-control is required for the clinical trials conducted in China, and it is necessary to identify new therapeutic targets and develop novel drugs for the key liver diseases, as well as preventive hepatitis $\mathrm{C}$ vaccines, and targeted therapy, TCM/ natural drugs and immunotherapy for liver cancer.

Keywords: clinical trials, liver diseases, hepatitis B, hepatitis C, liver cancer

\section{Introduction}

Liver diseases are a major cause of morbidity and mortality worldwide. More than a million people die every year due to viral hepatitis, which is also one of the most prevalent infectious diseases in China. Hepatitis B accounts for more than $70 \%$ of all incidences of viral hepatitis, and 10-20\% of chronic hepatitis B cases can progress to liver cirrhosis and $1-5 \%$ to liver cancer. ${ }^{1-4}$ The incidence of liver cancer in China is $36.5 / 100,000$, which is responsible for 418,000 deaths each year, accounting for $50 \%$ of the global liver cancer-related mortality. ${ }^{5,6}$ Given the serious socio-economic consequences of liver diseases, the research and development (R\&D) of therapeutic drugs has gained precedence in recent years.

Drug R\&D and production is an index of a country's economic and scientific capabilities. With improvements in living standards and amendments in national health policies, China has significantly increased investment in drug R\&D in recent years. 
Numerous drug clinical trials are registered every year, especially related to liver diseases. However, no overview has been conducted so far on the current R\&D for liver-specific drugs in China, and the actual situation regarding the development and evaluation of new drugs in clinical trials. In order to strengthen the supervision and management of drug clinical trials, promote transparency of results, and protect the rights and safety of the participating subjects, the State Food and Drug Administration (SFDA) has established a "Drug Clinical Trial Registration and Information Disclosure Platform" in accordance with the requirements of the World Health Organization (WHO) and international practices. In a 2013 addendum, SFDA stated that all approved clinical trials in China (including bioequivalence and PK trials, and phases I-IV) should be registered and all relevant information logged into www.cde.org.cn.

In this study, we reviewed the clinical trials on liver disease-related drugs published on the above platform before December 31, 2020. Our objective is to gain a better understanding of the current situation regarding the development of new drugs and provide a decisionmaking basis for further R\&D and regulatory guidelines.

\section{Methods}

The information of all clinical trials on liver diseases, including viral hepatitis, liver cancer, cirrhosis, nonalcoholic steatohepatitis, etc., entered before

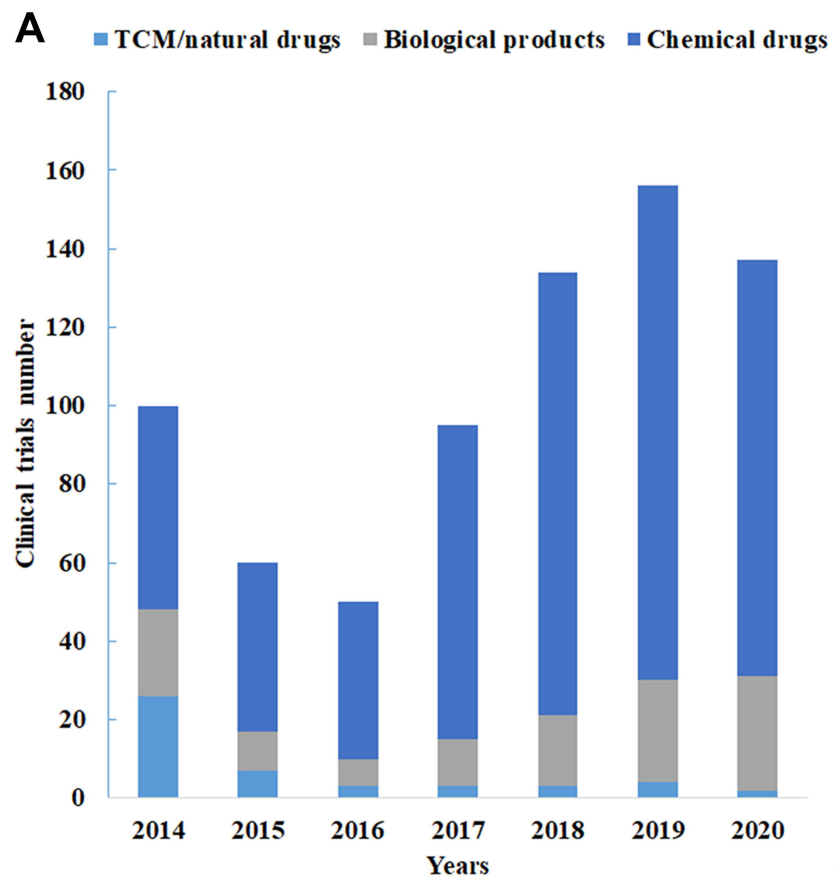

December 31, 2019, were extracted. The registration numbers, status, drug name, dosage form, indications, popular test topics, registration date, applicant's test stage, main investigator, etc. were analyzed.

\section{Results}

\section{Overall Situation Analysis} Number of Registrations

As of December 31, 2020, the drug clinical trial registration and information disclosure platform has published the information of 751 clinical trials are concerned with liver diseases, including 574 for chemical drugs (76.4\%), 128 for biological products (17.0\%) and $49(6.5 \%)$ for Traditional Chinese Medicine (TCM)/natural drugs. Furthermore, 19 of these trials are actively suspended and the remaining 732 are in progress or completed. The latter include 560 trials on chemical drugs, 124 on biological products and $48 \mathrm{TCM}$ /natural drugs.

The number of annual clinical trials registrations for liver diseases has been increasing on a yearly basis, and the number of clinical trial registrations reached 137 in 2020, as shown in Figure 1A. However, the number of clinical trials of TCM/natural medicines in the past 5 years is not exceeding 5 per year (Figure 1A). The spike in clinical trial registration post 2013 could be attributed to policy changes that led to supplementary registrations. Furthermore, $31.2 \%$ and 50.9\%

\section{B}

$\varpi$ TCM/natural drugs $\square$ Biological products $\square$ Chemical drugs

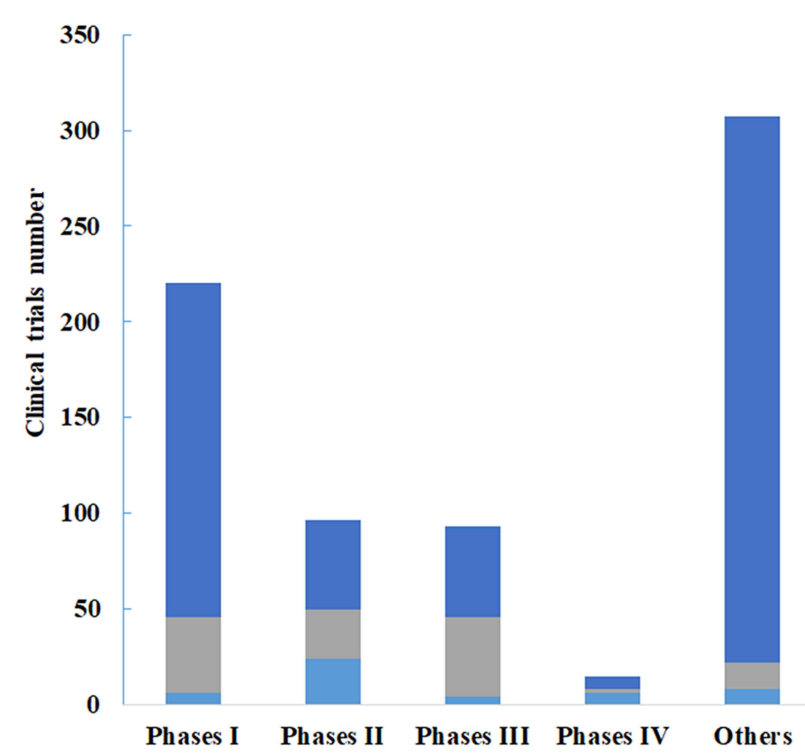

Figure I Annual numbers of clinical trials of initiated drug used for liver diseases in China (A); The phase of clinical trials of initiated drug used for liver diseases in China (B). 
of the trials on chemical drugs are respectively at Phase I and preclinical stages (bioequivalence and pharmacokinetics testing), whereas $66.1 \%$ of the biological products are at phases I and III of testing. In contrast, $50 \%$ of the clinical trials of $\mathrm{TCM} /$ natural drugs are at Phase II (Figure 1B).

\section{Distribution of Dosage Form}

The different dosage forms of the chemical, biological and $\mathrm{TCM} /$ natural drugs are summarized in Figure 2. Most chemical drugs $(90.9 \%)$ are administered as tablets and capsule, while 40 are injectables. In contrast, $98.4 \%$ of the biological products are in the injectable form. The dosage forms of TCM/natural drugs are the most varied, including pills, granules, capsules, tablets and injections. There are few clinical trials on new generation drug delivery systems, including six liposomes and four microspheres, all loaded with chemical therapeutics.

\section{Distribution of Clinical Research Institutions and Applicants}

More than $98 \%$ of the research institutions listed in the registered clinical trials are located in mainland China, and only nine major research centers are in other countries, such as Spain, the United States and Korea. Moreover,
$58.7 \%$ of the research centers are concentrated in Beijing, Shanghai, Jiangsu and Jilin province as of December 31, 2020, and a few are situated in northwest China but not in Tibet and Qinghai.

\section{Frequency of Trials}

Due to the generic nature of most drugs related to liver disease, several are part of multiple clinical trials. Based on the registration details, 35 drugs are being tested in more than five clinical trials. Tenofovir disoproxil fumarate tablets and tenofovir propofol fumarate tablets have the highest number of trials (30), followed by entecavir tablets (29). Furthermore, more than 10 clinical studies are registered for yimitasvir phosphate capsules, lenvatinib mesilate capsules, sorafenib tosylate tablets, seraprevir potassium tablets and tenofovir alafenamide tablets. For statistical analysis, the different dosage forms of a compound were considered the same drug.

\section{Indigenous Innovation Drugs for Liver Disease}

In document No. 51 published in 2016, SFDA classified innovative drugs, defined as those that have not been marketed in China or abroad, contain novel compounds with a clear structure, and with pharmacological effects

\section{$\square$ TCM/natural drugs $\quad \square$ Biological products $\quad \square$ Chemical drugs}

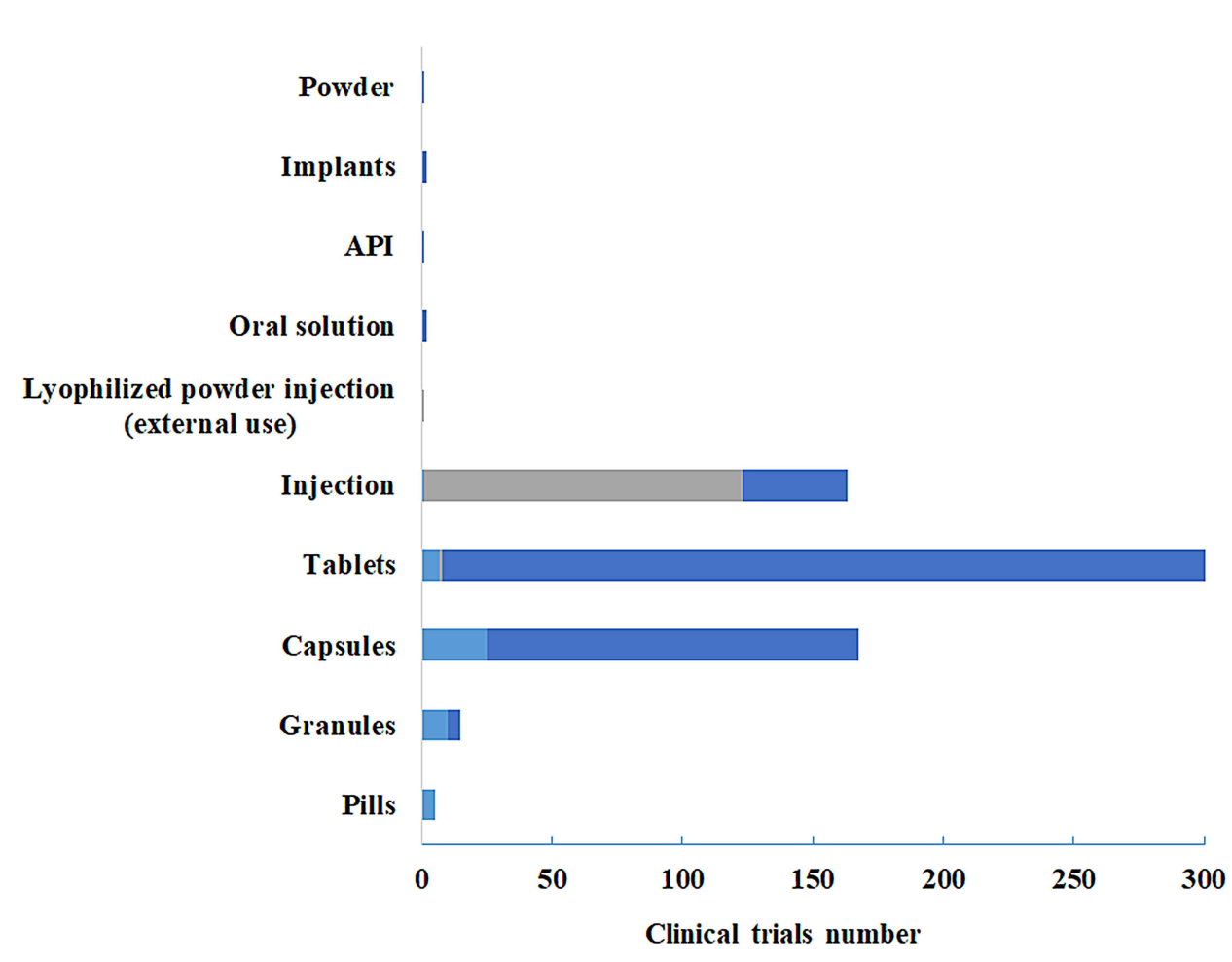

Figure 2 Distribution of dosage forms for clinical trials for liver diseases of chemical drugs, biological products and TCM/natural drugs. 
and clinical value, into a separate group. As shown in Table 1, 103 innovative drugs for liver diseases are currently in clinical testing, and the number of new applications is increasing. Among them, 24 are biological products and 79 are chemical drugs. The indications of innovative drugs in the field of liver diseases are mainly concentrated in the treatment of hepatitis $\mathrm{B}$, hepatitis $\mathrm{C}$, hepatocellular carcinoma, and many types of cancer including liver cancer. In addition, these innovative drugs are also used to treat drug-induced liver injury, viral hepatitis, prevent hepatitis B, liver fibrosis, cirrhosis ascites, prevent hepatitis E, amoeba liver abscess, non-alcoholic

Table I The Indigenous Innovation Drugs for Liver Disease in China Clinical Studies

\begin{tabular}{|c|c|c|}
\hline \multicolumn{2}{|l|}{ Indications } & \multirow[b]{2}{*}{$\begin{array}{c}\text { Drug Name } \\
\text { GLS4-methanesulfonate, isothiafludine, metacavir, pradefovir mesylate, HS-10234, QL-007, TQ- } \\
\text { A3334, therapeutic hepatitis B vaccine, recombinant human serum albumin/interferon alpha 2a } \\
\text { fusion protein for injection, hepalatide, tyrophentide, therapeutic injection of hepatitis } \\
\text { B adenovirus, HH-003, recombinant human serum albumin-interferon alpha 2a fusion protein } \\
\text { injection (yeast), imidol hydrochloride, APG-1387, octadecyloxyethyl-tenofovir, STSG-0002, } \\
\text { TVAX-008, TQA3729, PAI0I0, KL060332, HRS9950, HRS509I, HECI2II20, GST-HGI4I, GST- } \\
\text { HGI3I, ASC22 }\end{array}$} \\
\hline Viral hepatitis & Hepatitis B & \\
\hline & Hepatitis C & $\begin{array}{l}\text { Yimitasvir phosphate, serarivir potassium, ASCI6, furaprevir, coblopasvir, SH229, ASC08, } \\
\text { fupitavir, amphibavir, HEC74647PA, ZN6I68, HECII0II4, kangdaprevir sodium, ZN2007Na, } \\
\text { TQ-A3326, ASCI8 }\end{array}$ \\
\hline & Hepatitis B and C & Y type PEGylated recombinant human interferon $\alpha 2 b$ injection \\
\hline & Hepatitis & $\begin{array}{l}\text { Polyethylene glycol new integrated interferon mutant injection, recombinant human serum } \\
\qquad \text { albumin/interferon } \alpha 2 b \text { fusion protein for injection }\end{array}$ \\
\hline & Prevention of hepatitis B & Recombinant hepatitis B vaccine containing pre-S antigen (Pichia pastoris) \\
\hline & Prevention of hepatitis E & Recombinant hepatitis E vaccine \\
\hline \multirow[t]{2}{*}{ Liver cancer } & Liver cancer & $\begin{array}{l}\text { SHR-I2I0, ursolic acid nanoliposomes, tyroserleutide, donafenib tosylate, brivanib alaninate, } \\
\text { tislelizumab, recombinant humanized anti-PD-I monoclonal antibody injection, TQB2450, } \\
\text { chlorogenic acid, para-toluenesulfonamide, metatinib trometamol, MB07I33, lucitanib, chiauranib, } \\
\text { ATG-008, Hemay I02, recombinant human anti-human epidermal growth factor receptor } \\
\text { monoclonal antibody injection, ZSPI24I, dicycloplatin, AKI05, angiogenesis aprotinin, sintilimab, } \\
\text { recombinant anti-VEGF humanized monoclonal antibody injection, EMB-0I, GST-HGI6I, HJI97, } \\
\text { recombinant human PD-I antibody herpes simplex virus, CSI003 monoclonal antibody, } \\
\text { recombinant human calmodulin B for injection, 4-\{4-3-fluorophenoxy\} pyridine-2-carboxamide, } \\
\text { detorsertib, QLI604, DXI002, AKI04, ACT00I }\end{array}$ \\
\hline & $\begin{array}{c}\text { Intrahepatic } \\
\text { cholangiocarcinoma }\end{array}$ & Famitinib malate, HMPL-453 tartrate \\
\hline $\begin{array}{l}\text { Nonalcoholic } \\
\text { steatohepatitis }\end{array}$ & $\begin{array}{l}\text { Nonalcoholic } \\
\text { steatohepatitis }\end{array}$ & ZSPI60I, ZSP0678, TQA3563, HEC967I9, SYHAI805, SH2442, HS-I0356, ASC4I \\
\hline \multirow[t]{2}{*}{ Liver fibrosis } & $\begin{array}{l}\text { Liver fibrosis in chronic } \\
\text { viral hepatitis B }\end{array}$ & Hydronidone \\
\hline & Hepatic fibrosis & Fluorofenidone \\
\hline \multirow[t]{4}{*}{ Others } & Cirrhotic ascites & Recombinant human albumin injection \\
\hline & Amoebic liver abscess & Ornidazole \\
\hline & Liver function damage & SHR6390, SHR3680 \\
\hline & $\begin{array}{l}\text { Acute drug-induced liver } \\
\text { injury }\end{array}$ & Bicyclol \\
\hline
\end{tabular}


steatohepatitis, etc. The statistical analysis of the 103 innovative drugs was conducted on the basis of compounds, resulting in overlapping dosage forms and clinical trials of the same drug.

\section{Analysis of Clinical Indications Distribution of Clinical Indications}

The indications of clinical trials are viral hepatitis, liver malignant tumor, liver abscess, liver transplantation, congenital liver metabolic disease and other hepatitis-related diseases. A total of 438 clinical trials are related to viral hepatitis, especially hepatitis B and C that account for $93 \%$ of viral hepatitis-related diseases. In addition, there are 16 trials for preventive vaccines against hepatitis A, B and C, and 9 for hepatitis B with liver fibrosis. Liver malignancies are the focus of 172 clinical trials, of which 123 are being conducted only on liver cancer patients, and 45 have included patients with liver cancer, stomach cancer and lung cancer. Furthermore, drugs for liver abscess, liver transplantation, congenital liver metabolic disease, and other hepatic diseases like nonalcoholic steatohepatitis, alcoholic fatty liver and liver fibrosis are being tested in

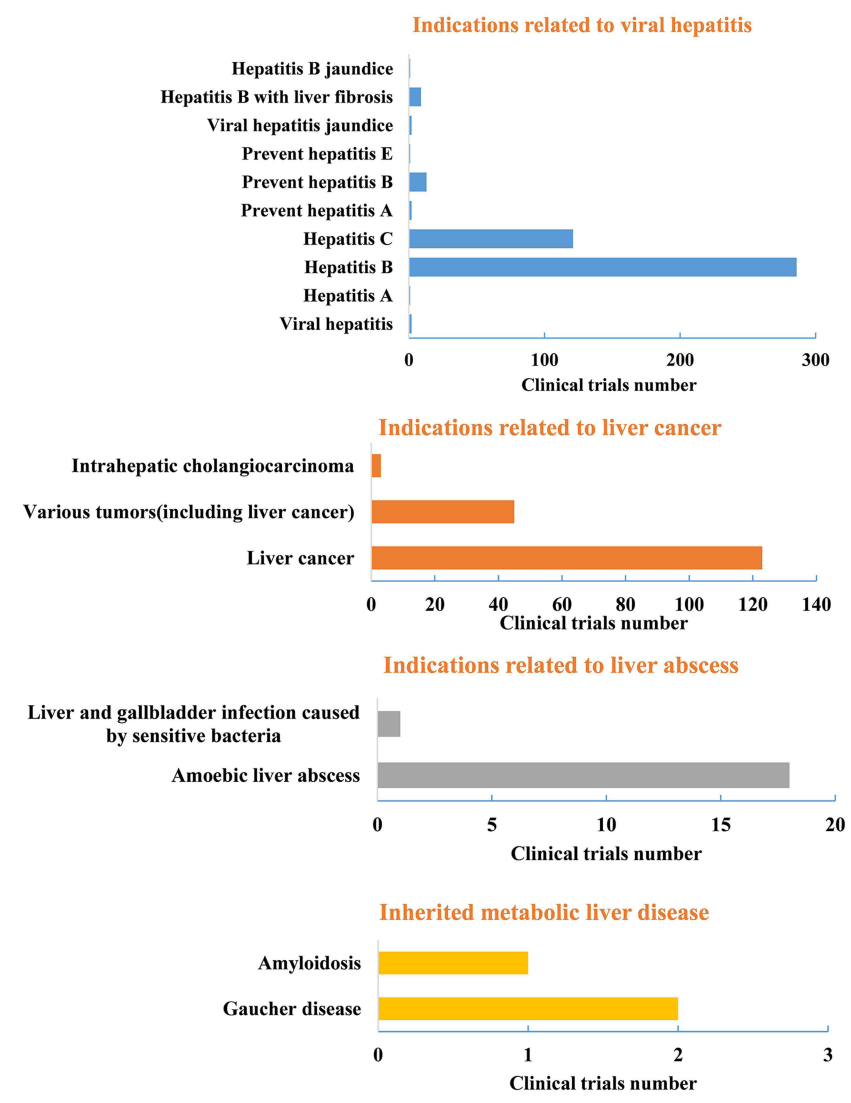

19, 15, 3 and 84 clinical trials respectively (Figure 3). Diseases of the digestive tract and metabolism, systemic infections, cardiovascular disorders often have liverrelated complications. Therefore, the liver-specific effects of drugs related to the above are also under investigation. For example, ornidazole and levornidazole are used to treat infections, and are effective against amoebic liver abscess as well. Likewise, torsemide and spironolactone can be used for treating cirrhotic ascites.

\section{Clinical Research Status of Drugs for Treating Hepatitis B}

The currently administered drugs for treating chronic hepatitis $\mathrm{B}(\mathrm{HBV})$ virus are classified into two categories: 1) immunomodulators including interferon alpha (IFN $\alpha$ ), peg-IFN $\alpha$, etc and 2) direct-acting antiviral agents, including nucleoside analogs and nucleotide analog prodrugs, such as lamivudine, telbivudine, adefovir dipivoxil, tenofovir disoproxil fumarate, etc.

Immunomodulators inhibit viral replication by induce an antiviral immune response by targeting specific checkpoints and immune cells, such as activating the JAK-STAT signaling pathway. ${ }^{7-9}$ Such drugs have the advantages of

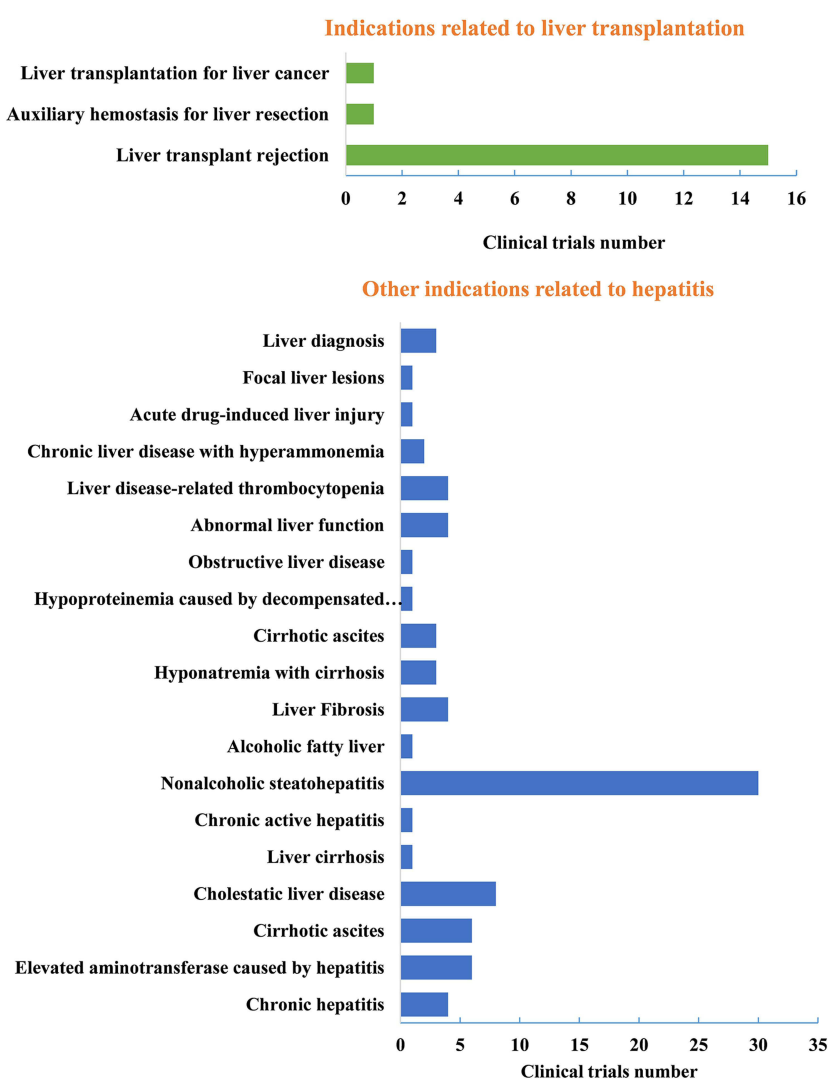

Figure 3 The distribution of clinical indications for liver diseases. 
high efficacy, high tolerance and low side effects. ${ }^{10,11}$ IFNs are broad-spectrum antiviral agents that bind to the specific receptors on immune cell surface, and trigger the production of antiviral proteins such as $2^{\prime} 5^{\prime}$ oligoadenylate synthase $\left(2^{\prime} 5^{\prime} \mathrm{AS}\right)$, protein kinase, phosphate diphosphate esterase, etc, which inhibit synthesis of viral nucleic acid and proteins. ${ }^{12,13}$ Although IFN is absorbed quickly, it has an extremely short half-life in circulation, and has extensive side effects. Conjugation of IFN with PEG can extend its half-life, and several clinical trials are underway on the effects of Peg-IFN. In addition, thymosin- $\alpha 1$ (T $\alpha 1)$ increases IL-2 synthesis, and upregulates the IL-2 highaffinity receptor on $\mathrm{T}$ cell precursors, which then effectively eliminate HBV. T $\alpha 1$ also reduces the cytotoxic effect of tumor necrosis factor (TNF $\alpha$ ), and is therefore a promising agent for hepatitis B treatment. ${ }^{14}$

Nucleoside analogs act directly on viral reverse transcriptase and block HBV replication, which do not directly inhibit cccDNA, viral transcription or translation, but instead block the reverse transcription activity of $\mathrm{HBV}$ polymerase, thereby inhibiting the synthesis of viral DNA from pre-genomic RNA. They compete with normal nucleotides during replication of viral DNA, and terminate DNA chain synthesis. Octadecyloxyethyl-tenofovir is a fat-soluble polymer derivative of tenofovir synthesized by adding long-chain octadecyloxyethyl, which significantly improves the permeability and absorption rate. Furthermore, in vitro pharmacokinetic and bioavailability tests showed a stronger inhibitory activity of octadecyloxyethyl-tenofovir compared to tenofovir. Nucleocapsid inhibitors including GLS4-methanesulfonate, RO7049389, JNJ-56136379, etc, induce defective nucleocapsid assembly by regulating core proteins at multiple points in the virus life cycle. The clinical trials of direct-acting antiviral agents are summarized in Table 2 .

In addition, peptides and vaccines are also promising drugs for hepatitis B treatment. Vaccines reverse immunotolerance and induce a cellular immune response. Clinical studies on intravenous injection of hepatitis B human immunoglobulin ( $\mathrm{pH} 4)$, hepatitis $\mathrm{B}$ vaccine, double plasmid HBV DNA vaccine and hepatitis $\mathrm{B}$ adenovirus injection are currently ongoing. Hepalatide is a new peptide drug that binds to the sodium taurocholate cotransporting polypeptide (NTCP) on hepatocytes, ${ }^{16}$ which blocks the interaction of HBV to its specific receptor and prevents virus entry.
Clinical Research of Drugs for Treatment of Hepatitis C In 2015, AASLD, EASL and APASL updated their guidelines for the prevention and treatment of chronic hepatitis $\mathrm{C}(\mathrm{CHC})$, and especially emphasized the use of direct antiviral agents (DAAs) that target NS3/NS4 protease, NS5A, NS5B RNA and NS4B and NS3 helicase proteins encoded by hepatitis $\mathrm{C}$ virus (HCV). ${ }^{17,18}$ The DAAs currently under development are summarized in Table 3.

NS3/4A protease inhibitors were the first DAAs to be developed for treating chronic hepatitis $\mathrm{C}$. The combination of NS3/4A protease inhibitors and standard treatment regimens increased the cure rate of hepatitis $\mathrm{C}$ by $\geq 30 \%$. Serarivir potassium, furaprevir, and kangdaprevir sodium are innovative new drugs developed in China. The clinical trial results and therapeutic effects of these agents have not been announced so far.

NS5B RNA polymerase inhibitors include both nucleoside and non-nucleoside inhibitors. ${ }^{19}$ The former directly target the active site of the polymerase, and nonnucleoside inhibitors target non-active sites and alter enzyme conformation, thereby inhibiting its function. Holybuvir is the first self-developed nucleoside $\mathrm{HCV}$ NS5B inhibitor to enter phase II/III clinical trials in China.

The NS5A RNA polymerase inhibitor regulates both virus replication and virion assembly. ${ }^{20}$ Novel NS5A inhibitors including yimitasvir phosphate, coblopasvir, fupitavir, ZN6168, etc, are currently being developed in China. Yimitasvir phosphate was first synthesized in 2012, and its structure is similar to ledipasvir and velpatasvir. Coblopasvir activity against GT-1-6 HCV and GT-3a HCV are respectively equivalent to and stronger than that of DCV. ZN6168 inhibits the replication of all six subtypes of NS5A virus, and its inhibitory effect against the NS5A-3a subtype replicon is 10 times more potent than that of DCV.

Amphibavir is an HCV NS4B inhibitor that was developed in China, and is currently the only indigenous hepatitis C NS4B-targeting drug in the clinical testing stage. ${ }^{21}$ It inhibits viral replication by blocking the interaction between the arginine-rich region of NS4B and the negative strand viral RNA. Finally, pegylated recombinant integrated IFN variant injection, Y-pegylated recombinant human IFN- $\alpha 2 b$ injection and RopegIFN- $\alpha 2 b$ (P1101) injection are the anti-hepatitis virus IFN drugs currently in clinical development. ${ }^{22}$ 
Table 2 Clinical Trials of Chemical Drugs Used to Treat Hepatitis B and Its Mechanism in China

\begin{tabular}{|c|c|}
\hline Drug Name & Mechanism \\
\hline Isothiafludine & Induces abnormal assembly of HBV core protein to form a vacuole nucleocapsid without viral nucleic acid \\
\hline Metacavir & Compete with HBV polymerase substrate deoxyguanosine triphosphate, thereby inhibiting the HBV-DNA replication process \\
\hline GLS4-methanesulfonate & Interfere with HBV virus capsid assembly, inhibit HBV DNA synthesis and replication \\
\hline Imidol hydrochloride & It may inhibit the membrane fusion between the virus and liver cells, inhibit HBV-DNA replication, and immunomodulate \\
\hline Pradefovir mesylate & Adefovir Prodrug, competitively incorporation with adenylate into the viral DNA chain, which inhibits viral replication \\
\hline Tyrophentide & $\begin{array}{l}\text { It can regulate the calcium-Pyk2 signaling pathway and } \mathrm{p} 2 \mathrm{I} \text { factor downstream of HBV replication, thereby inhibiting the } \\
\text { expression of cccDNA }\end{array}$ \\
\hline Hepalatide & Through specific binding to HBV hepatocyte infection receptor NTCP to blocking HBV infection \\
\hline HS- 10234 & Tenofovir prodrugs of monophosphoramide monoesters \\
\hline $\begin{array}{l}\text { Tenofovir alafenamide semi- } \\
\text { fumarate }\end{array}$ & Tenofovir disoproxil fumarate prodrug \\
\hline QL-007 & Capsid inhibitors, blocking viral capsid assembly \\
\hline APG-1387 & $\begin{array}{l}\text { It can make the liver cells infected by the virus have better sensitivity to the immune-mediated cells, thereby eliminating the } \\
\text { hepatitis B virus DNA and antigens mediated by specific } T \text { cells }\end{array}$ \\
\hline RO702053I & It is a selective TLR7 agonist, which enhances the body's host immune activity to eliminate hepatitis B virus \\
\hline RO706293I & $\begin{array}{l}\text { Hepatocyte uptake mediated by asialoglycoprotein receptor (ASGPR) can lead to hybridization of SSO LNA and HBV mRNA, } \\
\text { followed by RNAse H-mediated degradation }\end{array}$ \\
\hline GSK3389404 & $\begin{array}{l}\text { Viral protein inhibitors. By binding to hepatitis B virus mRNA and then preventing its transformation into hepatitis B virus } \\
\text { protein, and inhibit hepatitis B virus replication }\end{array}$ \\
\hline Octadecyloxyethyl-tenofovir & Introducing octadecoxyethyl into tenofovir to enhance its liposolubility and improve bioavailability \\
\hline RO7049389 & $\begin{array}{l}\text { Allosteric modulator of HBV core protein. By inducing the formation of abnormal HBV core aggregates, leading to defective } \\
\text { capsid assembly to inhibit HBV replication, and possibly restore the host's immune response to HBV }\end{array}$ \\
\hline JNJ-56136379 & HBV capsid protein assembly inhibitor \\
\hline TQ-A3334 & Highly selective TLR7 agonist that inhibits HBV by activating TLR7 to induce specific cytokines and chemokines \\
\hline $\mathrm{ABI}-\mathrm{H} 2 \mathrm{I} 58$ & HBV core protein allosteric modulator, blocking hepatitis B virus capsid protein assembly \\
\hline KL060332 & Hepatitis B virus capsid inhibitor \\
\hline HRS9950 & Toll-like receptor 8 agonists \\
\hline HRS509I & Nucleocapsid protein modulators \\
\hline $\mathrm{HECI} 121120$ & Undefined mechanism \\
\hline GST-HGI4I & Viral core protein inhibitors \\
\hline GST-HGI3। & Hepatitis B surface antigen expression inhibitors \\
\hline ASC22 & Antibody-dependent cell cytotoxicity; programmed cell death-I ligand-I inhibitors; T lymphocyte stimulants \\
\hline VIR-2218 & Hepatitis B virus replication inhibitors; RNA interference \\
\hline BRII-I 79 (VBI-260I) & B cell modulators; T lymphocyte modulators \\
\hline
\end{tabular}

Exclude the commercialized drugs as indications. 
Table 3 The Clinical Drugs and Mechanism for Treatment of Hepatitis C in China

\begin{tabular}{|l|c|}
\hline Mechanism & Drugs \\
\hline NS3/4A protease inhibitor & TMC435 \\
& $\begin{array}{c}\text { Furaprevir } \\
\text { Serarivir potassium } \\
\text { ASC08 } \\
\text { Kangdaprevir sodium }\end{array}$ \\
\hline NS5A protease inhibitor & $\begin{array}{c}\text { Yimitasvir phosphate } \\
\text { Coblopasvir } \\
\text { Ravidasvir } \\
\end{array}$ \\
\hline NS4B protease inhibitors & ZN6168 \\
\hline NS5B protease inhibitors & Amphihevir \\
\hline NS3 protease inhibitors & Holybuvir \\
\hline Combination drugs & ZN2007Na \\
\hline Broad-spectrum antiviral & ASCI8 ABT-450/ritonavir/ABT-267 \\
\hline
\end{tabular}

Exclude the commercialized drugs as indications.

\section{Clinical Research on Drugs for Liver Cancer}

The chemical drugs and its mechanism for liver cancer as listed in Table 4. Most ongoing clinical trials are focused on molecular targeted therapy and immunotherapy, and relatively few on chemotherapeutics and TCM.

The VEGF signaling pathway is an attractive therapeutic target given the vascular dysplasia seen in liver cancer, and several VEGFR antagonists including ATG-008, brivanib, lenvatinib mesylate and ramucirumab are currently in various phases of clinical testing. In addition, trials are also ongoing for the FGF pathway-targeting fisogatinib, mTORC1/mTORC2 inhibitor detorsertib, multi-target tyrosine kinase and Raf kinase inhibitor Mei-ta-fei-ni, etc.

Immune checkpoint blockers including antibodies targeting PD-1, PD-L1 and cytotoxic T lymphocyte antigen-4 (CTLA-4) can potentially be effective against advanced HCC. The anti-PD-1 antibodies currently in clinical trials for HCC include spartalizumab, AK105, TQB2450, CS1003, etc. Tremelimumab, a fully humanized monoclonal antibody against CTLA-4, binds to CTLA-4 expressed on the surface of activated $\mathrm{T}$ lymphocytes, and reverses the immunosuppressive state.

Icaritin soft capsules, basil capsules, ginsenoside $\mathrm{H}$ dropping pills and Kanglong capsules are the traditional Chinese medicines undergoing clinical testing for liver cancer. A multicenter, randomized open Phase III clinical trial is ongoing to compare the efficacy and safety of sorafenib and icaritin soft capsules for the first-line treatment of patients with PD-L1 positive advanced HCC. In addition, the efficacy and safety of resibufogenin as a firstline treatment for advanced HCC is also being tested in a multicenter, randomized, double-blind, doublesimulation phase III clinical trial. It is suggested that some TCM may have the same therapeutic effect as molecular targeted drugs in the treatment of HCC.

\section{Discussion}

Liver diseases, in particular hepatitis B, hepatitis C and liver cancer, are associated with considerable morbidity and mortality. An increasing number of clinical trials are registered each year in China for the treatment of liver diseases. However, generic drugs still account for a relatively large proportion of these studies. For example, there are 30 ongoing clinical trials for tenofovir disoproxil fumarate tablets, and the number increases to 37 (5\% of all clinical trials on liver diseases) when considering the different dosage forms. In recent years, the "National Innovation-Driven Development Strategy Outline", "13th Five-Year" National Science and Technology Innovation Plan, and "Pharmaceutical Industry Development Planning Guide" have set up the "Major New Drug Development" program to promote the development of new drugs, which has significantly increased the number of clinical trials of liver-specific innovative drugs.

Nucleotide analogs are still the most popular antihepatitis B drugs, although novel agents with greater bioavailability and lower risk of resistance are currently under development. For instance, immunotherapy is a highly promising option for hepatitis $\mathrm{B}$ treatment. IFNs also have a long-lasting therapeutic effect and a high clearance rate of viral surface antigens. However, their response rate is low and side effects are significant. Therefore, combination therapies are being considered as a viable alternative. $^{23}$ The current cocktail therapies under clinical development include nucleotide analogs with/out immunomodulatory drugs. The combination of different analogs can compensate for the limitations of a single drug, although it is not clear whether it can inhibit the latent cccDNA inside liver. Therefore, drugs that directly target cccDNA are the focus of future R\&D, along with development of effective delivery systems and minimizing offtarget effects of sequence-targeted nucleases.

An effective vaccine is necessary for prevention of $\mathrm{CHC}$, since it frequently progresses to cirrhosis and liver 
Table 4 The Clinical Chemical Drugs and Mechanism for Treatment of Liver Cancer in China.

\begin{tabular}{|c|c|}
\hline Drug Name & Mechanism \\
\hline Chlorogenic acid & Immunostimulants \\
\hline Dovitinib & Multi-target kinase inhibitor \\
\hline $\begin{array}{l}\text { Sulfonated Monophosphate Mannan } \\
\text { Oligosaccharide }\end{array}$ & PI-88 heparanase inhibitor \\
\hline Lenvatinib & Multi-target kinase inhibitor \\
\hline Tyroserleutide & $\begin{array}{l}\text { I Phosphatidylinositol } 3 \text { kinase inhibitors; apoptosis stimulants; intercellular adhesion molecule I } \\
\text { antagonists }\end{array}$ \\
\hline p-Toluenesulfonamide & Apoptosis stimulants; cathepsin B modulators; cell death stimulants \\
\hline Refametinib & Mitogen-activated protein kinase kinase inhibitors \\
\hline MSC2156II9J & c-Met inhibitor \\
\hline TLC388 HCl & Angiogenesis inhibitors; DNA topoisomerase I inhibitors \\
\hline Galunisertib & TGF- $\beta$ receptor type I (TGF- $\beta$ RI) kinase inhibitor, phosphotransferase inhibitors \\
\hline Erdafitinib & FGFR Kinase Inhibitor \\
\hline Miriplatin & DNA cross linking agents; DNA synthesis inhibitors \\
\hline Brivanib alaninate & Multi-target kinase inhibitor \\
\hline Chiauranib & $\begin{array}{l}\text { Angiogenesis inhibitors; aurora kinase B inhibitors; mitosis inhibitors; vascular endothelial growth } \\
\text { factor receptor antagonists }\end{array}$ \\
\hline ATG-008 & MTORCI protein inhibitors; MTORC2 protein inhibitors \\
\hline Hemayl02 & Not released \\
\hline Fisogatinib & FGFR4 Inhibitor \\
\hline Lenvatinib mesylate & Multi-target kinase inhibitor \\
\hline Mei-ta-fei-ni & Multi-target tyrosine kinase and Raf kinase inhibitor \\
\hline Detorsertib & $\mathrm{mTORCI} / \mathrm{mTORC2}$ inhibitor \\
\hline DX1002 & Tumor angiogenesis inhibitor \\
\hline АСТ00I & Combining with plasminogen activator inhibitor-I (PAI-I) and inhibit the PI3K/AKT pathway \\
\hline
\end{tabular}

Exclude the commercialized drugs as indications.

cancer, and the causative HCV is highly mutagenic. IFN combined with ribavirin (RBV) is no longer the standard recommended treatment for $\mathrm{CHC}$ due to the low sustained virological response (SVR) or complete cure rate, and the obvious adverse reactions and toxicity. ${ }^{24}$ So, In the absence of a vaccine, however, DAAs are promising therapeutic agents against hepatis $\mathrm{C}$, but may develop drug resistance after long-term use. Therefore, several clinical trials are testing the compound preparations of two or more DAAs, such as ABT-450/ritonavir/ABT-267 filmcoated tablet and Ledipasvir/Sofosbuvir tablet, which can significantly increase the SVR to more than $95 \%{ }^{25,26}$
Primary liver cancer ranks sixth in terms of incidence, and is the fourth most common cause of cancer-related mortality worldwide. ${ }^{5}$ It is a highly malignant disease characterized by a high degree of invasiveness and metastasis, and most patients are diagnosed at the advanced stage of cancer. The conventional therapies for primary liver cancer include surgical resection, liver transplantation or local ablation, and transcatheter arterial chemoembolization. Nevertheless, the clinical outcome and prognosis of patients with advanced liver cancer are very poor. Furthermore, the low tolerance of primary liver cancer patients to sorafenib and the emergence of drug resistance 
stresses the need to develop novel targeted drugs with greater therapeutic efficacy and fewer side effects. The clinical trials of targeted therapy drugs mainly include anti-angiogenesis agents, hepatocyte growth factor inhibitors, mammalian target rapamycin inhibitors, etc. In addition, immunotherapy is currently one of the most promising biological strategies for treating aggressive cancers, and can significantly prolong patient survival.

TCM formulations and compounds are also promising alternatives for treating liver diseases. Ginsenoside $\mathrm{H}$, and its major bioactive component 20 (S)-ginsenoside $\mathrm{Rh} 2$, strongly inhibit the growth of cancer cells. It can increase autophagy of HepG2 and Huh7 cells, inhibit $\beta$-catenin signaling, regulate immune response and down regulate VEGF, which eventually inhibit cellular growth and migration. ${ }^{27,28}$ Icaritin, a natural isopentene flavonoid also known as 3,5,7-trihydroxy-2-(4-hydroxymethylphenyl)-8-(3-methylbutenyl-2)-1,2-benzopyranone-4, is the bioactive compound of Epimedium. It inhibits tumor cell proliferation and induces apoptosis by targeting the IL-6/ STAT3, IGF1/STAT3 and MAPK/ERK signaling pathways. ${ }^{29,30}$ In addition, icaritin also induces the differentiation of immunosuppressive cells and thus exerts an immunomodulatory effect. ${ }^{31}$ The total glycosides of Rhizoma coptidis can significantly inhibit the replication of HBV cccDNA in cells, and thus targets an earlier stage compared to adefovir dipivoxil. Although all of the above drugs are in clinical trials, the complexity of traditional Chinese medicine formulations makes it challenging to develop novel drugs.

This study has some limitations that ought to be addressed. First, although clinical trial platform registration is mandatory as per NMPA regulations, we may have missed some clinical trials that were started prior to the implementation of new policy (before 2013). Nevertheless, we observed a significant spike in the number of clinical trials registered post 2013 due to supplementary registration. Secondly, the statistical analysis was conducted on the basis of the compounds, and the different dosage forms and clinical trials of the same drug were merged as a single candidate. Moreover, innovative drugs only analyze chemical drugs and biological products, while TCM/natural drugs are not analyzed due to their particularity. Thirdly, there is a certain discrepancy between the date of first announcement on the platform and the actual initiation of the clinical trial. We considered the former for the statistical analysis. Fourth, for statistics of major clinical research institutions, the statistically ranked first unit when there are multiple units.

\section{Conclusion}

Liver diseases include hepatitis, liver cirrhosis, liver cancer, etc. There is currently no effective treatment strategy that can simultaneously reduce liver injury and necrosis, and promote liver cell regeneration. Therefore, biotech companies and research institutes worldwide have invested heavily in drug R\&D for liver diseases. Based on our analysis, we infer stronger macro-control is required for the clinical trials conducted in China. For instance, proper policies and incentives should be formulated, and the development of innovative drugs should be encouraged. The current research foci in China are novel targets for hepatitis $\mathrm{B}$, hepatitis $\mathrm{C}$ and liver cancer, preventive hepatitis $\mathrm{C}$ vaccine, and targeted therapeutic drugs, TCM/natural drugs and immunotherapeutic drugs for liver cancer.

\section{Abbreviations}

CHC, chronic hepatitis C, CTLA-4, cytotoxic $\mathrm{T}$ lymphocyte antigen-4; DAAs, direct antiviral agents; DCV, daclatasvir; HBV, hepatitis B virus; HCC, hepatocellular carcinoma; $\mathrm{HCV}$, hepatitis $\mathrm{C}$ virus; IFNa, interferon alpha; NTCP, sodium taurocholate cotransporting polypeptide; R\&D, Research and Development; RBV, ribavirin; SFDA, State Food and Drug Administration; TCM, traditional Chinese Medicine; TLR-7, Toll-like receptor-7; TNF $\alpha$, tumor necrosis factor; T $\alpha 1$, thymosin$\alpha 1$; WHO, World Health Organization.

\section{Acknowledgment}

Thanks are due to Yuling Liu for assistance with the data collation in the process of manuscript revision.

\section{Funding}

This study was financially supported by the Fundamental Research Funds for the Central public welfare research institutes (ZZ13-YQ-059).

\section{Disclosure}

The authors declare that they have no conflicts of interest in this work.

\section{References}

1. McBride G. Hepatitis B virus-induced liver cancer in Asian Americans: a preventable disease. J Natl Cancer Inst. 2008;100 (8):528-529. doi:10.1093/jnci/djn120 
2. Yan YP, Su HX, Ji ZH, Shao ZJ, Pu ZS. Epidemiology of hepatitis $\mathrm{B}$ virus infection in China: current status and challenges. J Clin Transl Hepatol. 2014;2(1):15-22. doi:10.14218/JCTH.2013.00030

3. Zhou Y, Wan Y, Ye ZW, He Z, Liu Q, Shi Y. How hepatitis B virus causes cirrhosis and liver cancer. Med Hypotheses. 2017;108:52-53. doi:10.1016/j.mehy.2017.08.005

4. Ganem D, Prince AM. Hepatitis B virus infection--natural history and clinical consequences. $N$ Engl J Med. 2004;350(11):1118-1129. doi:10.1056/NEJMra031087

5. Lin L, Yan L, Liu Y, Yuan F, Li H, Ni J. Incidence and death in 29 cancer groups in 2017 and trend analysis from 1990 to 2017 from the Global Burden of Disease Study. J Hematol Oncol. 2019;12(1):96. doi:10.1186/s13045-019-0783-9

6. Lin L, Yan L, Liu Y, Qu C, Ni J, Li H. The burden and trends of primary liver cancer caused by specific etiologies from 1990 to 2017 at the global, regional, national, age, and sex level results from the Global Burden of Disease Study 2017. Liver Cancer. 2020;9 (5):563-582. doi:10.1159/000508568

7. Palumbo E. New drugs for chronic hepatitis B: a review. Am J Ther. 2008;15(2):167-172. doi:10.1097/MJT.0b013e318155a191

8. Hadziyannis SJ, Papatheodoridis GV. Treatment of HBeAg negative chronic hepatitis B with new drugs (adefovir and others). J Hepatol. 2003;39(Suppl 1):S172-176. doi:10.1016/S0168-8278(03)00334-9

9. Fanning GC, Zoulim F, Hou J, Bertoletti A. Therapeutic strategies for hepatitis B virus infection: towards a cure. Nat Rev Drug Discov. 2019;18(11):827-844. doi:10.1038/s41573-019-0037-0

10. Sasai M, Yamamoto M. Pathogen recognition receptors: ligands and signaling pathways by Toll-like receptors. Int Rev Immunol. 2013;32 (2):116-133. doi:10.3109/08830185.2013.774391

11. Janssen HLA, Brunetto MR, Kim YJ, et al. Safety, efficacy and pharmacodynamics of vesatolimod (GS-9620) in virally suppressed patients with chronic hepatitis B. J Hepatol. 2018;68(3):431-440. doi:10.1016/j.jhep.2017.10.027

12. Manns MP. Current state of interferon therapy in the treatment of chronic hepatitis B. Semin Liver Dis. 2002;22(Suppl 1):7-13. doi:10.1055/s-2002-35695

13. Arase Y, Tsubota A, Suzuki Y, et al. A pilot study of thymosin alpha1 therapy for chronic hepatitis B patients. Intern Med. 2003;42 (10):941-946. doi:10.2169/internalmedicine.42.941

14. Saruc M, Ozden N, Turkel N, et al. Long-term outcomes of thymosin-alpha 1 and interferon alpha-2b combination therapy in patients with hepatitis $\mathrm{B}$ e antigen ( $\mathrm{HBeAg}$ ) negative chronic hepatitis B. J Pharm Sci. 2003;92(7):1386-1395. doi:10.1002/jps.10401

15. Clark DN, Hu J. Unveiling the roles of HBV polymerase for new antiviral strategies. Future Virol. 2015;10(3):283-295. doi:10.2217/ fvl.14.113

16. Liu XJ, Liu C, Zhu LY, et al. Hepalatide ameliorated progression of nonalcoholic steatohepatitis in mice. Biomed Pharmacother. 2020;126:110053. doi:10.1016/j.biopha.2020.110053
17. Kiser JJ, Flexner C. Direct-acting antiviral agents for hepatitis C virus infection. Annu Rev Pharmacol Toxicol. 2013;53 (1):427-449. doi:10.1146/annurev-pharmtox-011112-140254

18. Spengler U. Direct antiviral agents (DAAs) - A new age in the treatment of hepatitis $\mathrm{C}$ virus infection. Pharmacol Ther. 2018;183:118-126. doi:10.1016/j.pharmthera.2017.10.009

19. Soriano V, Vispo E, de Mendoza C, et al. Hepatitis C therapy with HCV NS5B polymerase inhibitors. Expert Opin Pharmacother. 2013;14(9):1161-1170. doi:10.1517/14656566.2013.795543

20. Gitto S, Gamal N, Andreone P. NS5A inhibitors for the treatment of hepatitis C infection. J Viral Hepat. 2017;24(3):180-186. doi:10.1111/jvh.12657

21. Tao X, Wang N, Wang J, et al. Preclinical evaluation of Amphihevir, a first-in-class clinical Hepatitis C virus NS4B inhibitor. Antimicrob Agents Chemother. 2019;63(12). doi:10.1128/AAC.01237-19.

22. Lin L, Chen Y, Yan L, et al. Analysis of clinical trials of new drugs in China as of 2019. Drug Discov Today. 2020;25(12):2080-2088. doi:10.1016/j.drudis.2020.09.030

23. A 4-drug combination (Viekira Pak) for hepatitis C. JAMA. 2015;313:1857-1858.

24. Opar A. Excitement grows for potential revolution in hepatitis C virus treatment. Nat Rev Drug Discov. 2010;9(7):501-503. doi: $10.1038 / \mathrm{nrd} 3214$

25. Kowdley KV, Gordon SC, Reddy KR, et al. Ledipasvir and sofosbuvir for 8 or 12 weeks for chronic HCV without cirrhosis. $N$ Engl J Med. 2014;370:1879-1888.

26. Halfon P, Sarrazin C. Future treatment of chronic hepatitis C with direct acting antivirals: is resistance important? Liver Int. 2012;32 (Suppl 1):79-87. doi:10.1111/j.1478-3231.2011.02716.x

27. Zhang J, Li W, Yuan Q, et al. Transcriptome analyses of the anti-proliferative effects of 20(S)-ginsenoside Rh2 on HepG2 cells. Front Pharmacol. 2019;10:1331. doi:10.3389/fphar.2019.01331

28. Song BK, Kim KM, Choi KD, Im WT. Production of the Rare Ginsenoside Rh2-MIX (20(S)-Rh2, 20(R)-Rh2, Rk2, and Rh3) by enzymatic conversion combined with acid treatment and evaluation of its anti-cancer activity. J Microbiol Biotechnol. 2017;27 (7):1233-1241. doi:10.4014/jmb.1701.01077

29. Li Q, Huai L, Zhang C, et al. Icaritin induces AML cell apoptosis via the MAPK/ERK and PI3K/AKT signal pathways. Int $J$ Hematol. 2013;97(5):617-623. doi:10.1007/s12185-013-1317-9

30. Zhu J, Li Z, Zhang G, et al. Icaritin shows potent anti-leukemia activity on chronic myeloid leukemia in vitro and in vivo by regulating MAPK/ERK/JNK and JAK2/STAT3 /AKT signalings. PLoS One. 2011;6(8):e23720. doi:10.1371/journal.pone.0023720

31. Hao H, Zhang Q, Zhu H, et al. Icaritin promotes tumor T-cell infiltration and induces antitumor immunity in mice. Eur J Immunol. 2019;49(12):2235-2244. doi:10.1002/eji.201948225

\section{Publish your work in this journal}

Drug Design, Development and Therapy is an international, peerreviewed open-access journal that spans the spectrum of drug design and development through to clinical applications. Clinical outcomes, patient safety, and programs for the development and effective, safe, and sustained use of medicines are a feature of the journal, which has also been accepted for indexing on PubMed Central. The manuscript management system is completely online and includes a very quick and fair peer-review system, which is all easy to use. Visit http://www. dovepress.com/testimonials.php to read real quotes from published authors. 